\title{
Analisis Jumlah e Node B LTE Untuk Kota Balikpapan
}

\author{
Maria Ulfah \\ Teknik Elektronika \\ Politeknik Negeri Balikpapan \\ Jalan Soekarno Hatta Km.8 Balikpapan 76126 \\ Email : maria.ulfah@poltekba.ac.id
}

\begin{abstract}
This study was conducted to determine the number of e node B for LTE 4G technology in Balikpapan City. The calculation of the number of e node $B$ in terms of telecommunications network planning is needed, especially for new technologies to be deployed. In the studies used bandwidth of $10 \mathrm{MHz}$, calculation of the number of $e$ node $B$ until the next 5 years the number of e node is obtained for the first year $126 e$ node $B$ that every year the number of e node B has increased to 143 last year calculation e Node.
\end{abstract}

Keywords : e node B, LTE, Bandwidth

\begin{abstract}
Abstrak
Penelitian ini dilakukan untuk menentukan jumlah e node B untuk teknologi 4G LTE di kota Balikpapan. Perhitungan jumlah e node $B$ dalam hal perencaan jaringan telekomunikasi sangat diperlukan terutama bagi teknologi baru yang akan digelar. Pada penelitian memakai bandwith sebesar $10 \mathrm{MHz}$, dilakukan perhitungan jumlah e node B sampai 5 tahun ke depan didapatkan jumlah e node untuk tahun pertama 121e node B yang setiap tahunnya jumlah e node B mengalami peningkatan sampai tahun perhitungan terakhir 143 e Node B.
\end{abstract}

Kata kunci : e node B, LTE, Bandwidth

\section{Pendahuluan}

3GPP Long Term Evolution (LTE) adalah nama yang diberikan untuk standar teknologi komunikasi baru yang dikembangkan oleh 3GPP untuk mengatasi peningkatan permintaan kebutuhan akan layanan komunikasi, LTE adalah lanjutan dari evolusi $2 \mathrm{G}$ dan $3 \mathrm{G}$ sistem dan juga untuk menyediakan layanan tingkat kualitas yang sama dengan jaringan wired. Serta, untuk memberikan kecepatan data yang lebih tinggi, latency (jumlah waktu yang dibutuhkan paket data untuk berpindah di seluruh koneksi jaringan) yang lebih rendah, spectrum yang lebih luas dan teknologi paket radio yang lebih optimal.

Pada LTE kecepatan transfer data mencapai 100Mbps pada sisi downlink dan $50 \mathrm{Mbps}$ pada sisi uplink. Berikut adalah gambar yang menunjukkan perkembangan 3GPP dari release 99 hingga release 8 :

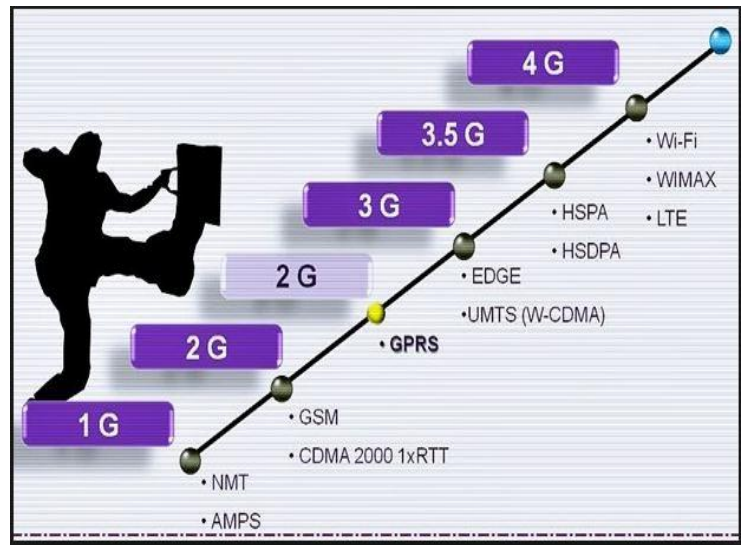

Gambar 1.1 Evolusi Sistem Komunikasi Bergerak 
Arsitektur Jaringan 4G LTE sebagai berikut:

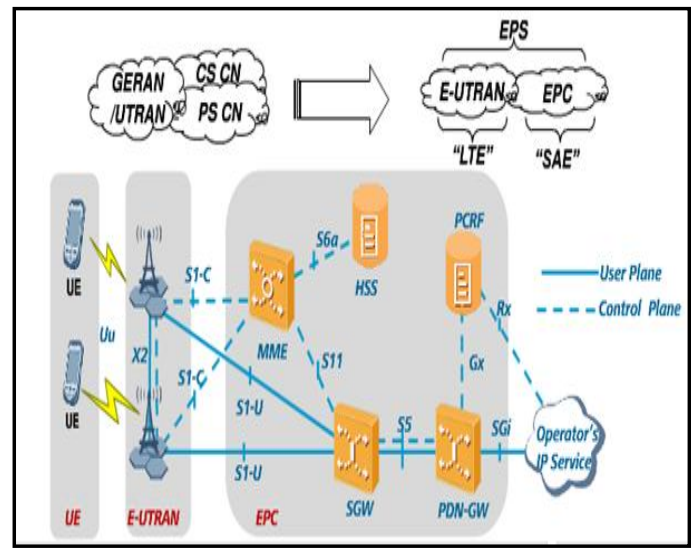

Gambar 2.2 Arsitektur Jaringan 4G

Keterangan:

- User Equipment (UE)

User equipment adalah perangkat dalam LTE yang terletak paling ujung dan berdekatan dengan user.

\section{- E-UTRAN}

Envolved UMTS Terresterial Radio Access Network (E-UTRAN) adalah sistem arsitektur LTE yang memiliki fungsi menangani sisi radio akses dari UE ke jaringan core. Pada sistem LTE E-UTRAN hanya terdapat satu komponen yakni Envolved Node B (eNode B)

\section{- Evolved Packet Core (EPC)}

EPC terdiri dari MME (Mobility Management Entity), SGW (Serving Gateway), HSS (Home Subscription Service), PCRF (Policy and Charging Rules Function), dan PDN-GW (Packet Data Network Gateway).

\section{Metode Penelitian}

Metode yang dipakai dalam penelitian ini berupa langkah kerja serta rangkaian kegiatan sebagai berikut :

Penelitian ini diawali dengan tinjauan pustaka serta pengumpulan data sekunder yang diperoleh dari Disdukcapil Kota Balikpapan seperti luas daerah Balikpapan, usia penduduk produktif.

Selanjutnya perhitungan prediksi pelanggan, jumlah kanal, traffic demand, jumlah sel, luas sel dan perhitungan jumlah eNodeB

\section{Hasil Penelitian}

Untuk menghitung jumlah e node B kota Balikpapan diperlukan data pendukung sebagai berikut:

- Luas kota Balikpapan : 503,3 km²

- Bandwidth alokasi $: 10 \mathrm{MHz}$

- Bandwidth RF : $200 \mathrm{KHz}$

- User/Kanal : 8

- Cluster :3

- Traffic per User $\quad: 30 \mathrm{mE}$

Tabel 1. Pembagian Wilayah Adm Balikpapan

\begin{tabular}{|l|l|l|l|}
\hline No & Kecamatan & $\begin{array}{l}\text { Jumlah } \\
\text { Penduduk } \\
(\text { Jiwa })\end{array}$ & $\begin{array}{l}\text { Luas Wilayah } \\
\left(\mathrm{Km}^{2}\right)\end{array}$ \\
\hline 1 & Balikpapan Timur & 86819 & 137.1 \\
\hline 2 & Balikpapan Barat & 107062 & 179.6 \\
\hline 3 & Balikpapan Utara & 164081 & 132 \\
\hline 5 & $\begin{array}{l}\text { Balikpapan } \\
\text { Sengah }\end{array}$ & 122103 & 11 \\
\hline 6 & Balikpapan & 154436 & 37.7 \\
\hline & \begin{tabular}{l} 
Total \\
\hline
\end{tabular} & 736807 & 503.3 \\
\hline
\end{tabular}

Sumber : Disduk Capil

Jumlah penduduk Balikpapan per Desember 2015 : 736807 Jiwa

Tabel .2 Penggolongan Penduduk

\begin{tabular}{|c|c|c|}
\hline No & Golongan Umur & Jumlah \\
\hline 1 & $0-14$ & 189342 \\
\hline 2 & $15-59$ & 505594 \\
\hline 3 & $60 \leq$ & 40914 \\
\hline
\end{tabular}

Sumber : Disduk Capil 
Usia antara 15- 59 tahun dianggap sebagai usia produktif,

* Pertumbuhan penduduk 4,22\%

\section{A. Prediksi Pelanggan (User)}

Untuk menghitung jumlah prediksi user selama 5 tahun ke depan dengan mengggunkan persamaan

Un $=\operatorname{Uo}_{\ldots \ldots \ldots \ldots \ldots \ldots \ldots \ldots(1)}(1+\mathrm{Fp})^{\mathrm{n}}$

Keterangan :

Un $=$ prediksi jumlah user

Uo = jumlah user pada saat tahun perencanaan

$\mathrm{Fp}=$ faktor pertumbuhan pelanggan

$\mathrm{n} \quad=$ jumlah tahun prediksi

\section{Tabel 3. Prediksi User}

\begin{tabular}{|c|c|}
\hline Tahun ke & Prediksi User (Jiwa) \\
\hline $1(2017)$ & 526930 \\
\hline $2(2018)$ & 549166 \\
\hline $3(2019)$ & 572341 \\
\hline $4(2020)$ & 596494 \\
\hline $5(2021)$ & 621666 \\
\hline
\end{tabular}

Sumber : Penulis

\section{B. Jumlah Kanal}

$\mathrm{N}$

$$
=
$$

$$
\frac{\mathrm{BW}}{200 \mathrm{KHz}} \times
$$

$\frac{8}{\text { kluster }}$

Maka didapatkan jumlah kanal sebanyak

134 kanal (Tabel Erlang B, GOS 5\%)

\section{Traffic Demand}

$\mathrm{A}=$ jumlah estimasi user $\mathrm{x}$ trafik rata - rata

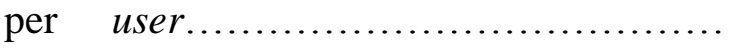

Dengan rumusan di atas didapatkan hasil seperti pada tabel di bawah ini:
Tabel 4.Traffic Demand

\begin{tabular}{|c|c|}
\hline Tahun ke & Traffic Demand (E) \\
\hline $1(2017)$ & 15807,93 \\
\hline $2(2018)$ & 16475,01 \\
\hline $3(2019)$ & 17170,26 \\
\hline $4(2020)$ & 17894,85 \\
\hline $5(2021)$ & 18650,01 \\
\hline
\end{tabular}

Sumber : Penulis

\section{Jumlah Sel}

Jumlah Sel $=\frac{A_{\text {tot }}}{A_{\text {sel }}}$

Dengan rumusan di atas didapatkan hasil seperti pada table di bawah ini (Tabel Erlang B , Qos $=5 \%, \mathrm{~N}=134$ Kanal)

Tabel 5. Jumlah sel

\begin{tabular}{|c|c|}
\hline Tahun ke & Jumlah sel \\
\hline $1(2017)$ & 121 \\
\hline $2(2018)$ & 126 \\
\hline $3(2019)$ & 131 \\
\hline $4(2020)$ & 137 \\
\hline $5(2021)$ & 143 \\
\hline
\end{tabular}

Sumber: Penulis

\section{E. Luas Sel (L)}

Luas Sel $=\frac{\text { Luas }_{\text {daerah }}}{\Sigma \text { Sel }}$

Jari-jari sel $\left(\mathbf{R}_{\text {sel }}\right)$

$\mathrm{R}_{\mathrm{sel}}=\sqrt{\frac{L_{s e l}}{2,6}}$.

Didapatkan table hasil perhitungan sebagai berikut: 
Tabel 6. Luas dan Jari-jari2 Sel

\begin{tabular}{|c|c|c|}
\hline Tahun ke & Luas sel $\left(\mathrm{km}^{2}\right)$ & Jari-jari Sel $(\mathrm{km})$ \\
\hline $1(2017)$ & 4,159 & 1,599 \\
\hline $2(2018)$ & 3,994 & 1,536 \\
\hline $3(2019)$ & 3,841 & 1,477 \\
\hline $4(2020)$ & 3,673 & 1,412 \\
\hline $5(2021)$ & 3,519 & 1,353 \\
\hline
\end{tabular}

Sumber: Penulis

Untuk perhitungan jumlah e Node B bias didapatkan dengan memakai perhitungan:

Jumlah e Node B = Luas daerah / Luas Sel

Didapatkan table seperti berikut:

Tabel 7. Jumlah e Node B

\begin{tabular}{|c|c|}
\hline Tahun ke & Jumlah e Node B \\
\hline $1(2017)$ & 121 \\
\hline $2(2018)$ & 126 \\
\hline $3(2019)$ & 131 \\
\hline $4(2020)$ & 137 \\
\hline $5(2021)$ & 143 \\
\hline
\end{tabular}

Sumber : Penulis

\section{Kesimpulan}

Berdasarkan hasil perhitungan untuk mengetahui jumlah e Node B teknologi $4 \mathrm{G}$ LTE di kota Balikpapan didapatkan sejumlah 121 untuk tahun 2017 yang akan terus mengalami peningkatan sampai tahun 2021 sejumlah 143.

Peningkatan ini sesuai dengan asumsi peningkatan jumlah pengguna (user) setiap tahunnya juga, sehingga pengguna akan dapat menikmati layanan 4G LTE secara maksimal dengan penambahan jumlah e Node B yang sejalan berarti bertambah besar daerah jangkauan (coverage area).

\section{Saran}

Diperlukan penelitian lebih lanjut mengenai simulasi coverage area dengan jumlah e Node B hasil perhitungan agar dapat diketahui daerah jangkauan (coverage area)

\section{Daftar Pustaka}

Kurniawan. Uke, Prihatmoko. Galuh, Kusuma. Denny, Dedi . Sigit, 2012, Fundamental Teknologi Seluler, Rekayasa Sains, Bandung

Wardhana.Lingga, Dewantoro. Anton, Harto Isybel, Mahardika. Dika, Hikmaturohman. Alfin, 2014, $4 G$ Handbook Edisi Bahasa Indonesia, w3.nulisbuku.com, Jakarta

T.S Rappaport, 2002, Wireless Communication: Principles and Practice, Prentice Hall

Wardhana, Lingga, 2011, 2G/3G RF Planning and Optimization for Consultant (plus introduction to $4 G$ ), w3.nulisbuku.com, Jakarta

Kurniawan. Uke, Dwi. Gunadi, Wibisono. Gunawan, 2008, Konsep Teknologi Seluler, Informatika, Bandung 